\title{
Equity in healthcare utilisation and cost of treatment in Western India
}

\section{Anil Gumber ${ }^{1}$ (iD}

Accepted: 19 October 2020 / Published online: 10 February 2021

(C) The Author(s) 2021

\begin{abstract}
The paper compares the morbidity and healthcare utilisation scenario prevalent in Gujarat and Maharashtra as well as for all - India over the last 35 years by exploring the National Sample Surveys data for 1980-81, 1986-87, 1995-96, 2004, and 2014. The differentials and trends in morbidity rate, health seeking behaviour, use of public and private providers for inpatient and outpatient care and associated cost, and burden of treatment are analysed by population groups. Changes in people's demand for health services are correlated with the supply factors i.e. expansion of public and private health infrastructure. Rising cost and burden of treatment on the poor are examined through receipt of free inpatient and outpatient services as well as the extent of financial protection under the health insurance schemes received by them. Overtime, morbidity rates have gone up, with several folds increase in select states; the reliance on public provision has gone down substantially despite being cheaper than the private sector; and cost of treatment at constant prices increased considerably even for the poor. Hospitalisation costs were higher among insured than the non-insured households in several states irrespective of whether resident in rural or urban areas (Haryana, Maharashtra, Himachal Pradesh, and Assam have reported that insured households ended-up paying almost double the hospitalisation expenses in 2014). Leaving aside Kerala (where insured households have paid just a half of the cost of the non-insured), this clearly reflects the widespread prevalence of moral hazard and insurance collusion in India.
\end{abstract}

Keywords Healthcare use · Treatment cost $\cdot$ Health insurance $\cdot$ Out-of-pocket expenditure . Poor $\cdot$ BPL

JEL I12 Health Behaviour · Health Insurance $\cdot$ Public and Private $\cdot$ I14 Health and Inequality

Anil Gumber

a.gumber@shu.ac.uk

1 Faculty of Health and Wellbeing, Senior Health Economist, Sheffield Hallam University,

Sheffield S10 2BP, UK 


\section{Background}

A decade ago, the concept of universal health coverage (UHC) was evolved by the WHO to achieve global enhancement in population health through improvement in access and reduction in health seeking barriers especially across developing countries. The UHC means that all people receive the quality, essential health services they need, without being exposed to financial hardship (World Health Organisation, 2015). In order to achieve UHC in India, an updated National Health Policy was issued by Government of India in 2015 with objectives to improve access to quality health services at affordable cost to the people. This paper is primarily aimed to make an assessment of the progress made by India as well as by Gujarat and Maharashtra so far in terms of providing healthcare access, quality of health services and reducing the financial hardship faced by the rural and urban population and the poor.

Gujarat and Maharashtra are well-known as the most industrialised states of India. However, in terms of per capita income Maharashtra ranks 5th and Gujarat 7th among 17 major states (Kerala, Punjab, and Haryana are on the top). According to the United Nations Human Development report (UNDP, 2014), Maharashtra ranks 3rd in terms of life expectancy at birth and 5th on human development index, whereas the respective ranks for Gujarat are far behind at 9th and 7th, which are just closer to the national average. Kerala tops in health and human development index which is followed by Punjab. Thus, Gujarat which is much closer to the national average in terms of economic, health, and human development indicators, with Maharashtra makes an interesting study to understand how the various sections of population have maintained their health status over a span of 35 years.

This paper presents the pattern of morbidity, healthcare utilisation, and associated out-of-pocket (OOP) expenditure on the treatment by rural and urban residents of Gujarat and Maharashtra. The attempt is made to highlight the trends in key utilisation indicators separately for inpatient and outpatient care, whilst analysing five-time points data from the NSS conducted during 1980-81, 1986-87, 1995-96, 2004, and 2014. However, the key results from the latest 75th Round for 2017-18 are published (Government of India, 2019), the individual records data are still not available from the NSSO and thus not included in the analysis. This paper further explores health insurance enrolment/coverage and the extent of financial protection received by households from the most recent survey of 2014. The comprehensive data analysis will point towards whether Gujarat and Maharashtra have made significant progress towards achieving the UHC goals in terms of improving equity in accessing healthcare services and reducing financial hardship to meet the catastrophic treatment cost.

The paper is structured in 6 sections, including the introduction. Section 2 presents an overview of the National Sample Survey (NSS) data and methods. Section 3 examines the public and private health infrastructure available for rural and urban population and explores the supply effect on the demand for health services. Morbidity and health seeking behaviour of rural and urban population over 35 years is explored in Sect. 4. Section 5 examines the reliance on public or private health services for inpatient and outpatient care. Section 6 discusses the associated cost and burden of treatment by rural and urban residents and the poor. Finally, the extent of health insurance coverage and financial protection received by the poor and non-poor households in 2014 is presented in Sect. 7. The last section presents the summary and conclusion. 


\section{National sample survey data and methods}

The National Sample Survey (NSS) was set up by the Government of India in 1950 as a continuing system of multi-purpose surveys designed to fill up gaps in the data required for planning for economic and social development. During the last seven decades of its yearly socio-economic surveys, the morbidity theme was given attention in 12 rounds and the healthcare utilisation and expenditure on treatment only in 6 rounds (beginning from 35th round, July 1980-June 1981-Table 1). The surveys on morbidity undertaken during the 1950s, 1960s, and 1970s were rather exploratory in nature. Their aims were to identify better data collection methods and instruments relating to recall period, use of proxy respondents, definition of an illness, and items of information on utilisation of health services from relatively smaller sample household. Since 1980-81 onwards a very important theme on the utilisation of health services for treatment was included with two main objectives: (a) to make an assessment of the benefits received from public investment in health services, and (b) to understand the broader health needs of various sections of the society. Detailed concepts and measurements of morbidity and utilisation of health services adopted in various NSS rounds are discussed elsewhere (Gumber and Berman 1997). Although conceptual changes between rounds limit some comparability overtime the NSS data on morbidity and health care utilisation have greatly enriched our knowledge and understanding of the subject. A glance of incidence/prevalence of morbidity in rural and urban India since 1953 is shown in Table 1.

Unfortunately, the 1980-81 survey data could not be processed due to delays in the availability of required computer facilities. Therefore, the tabulated data of 1986-87 survey were the first results on the utilization of health services in India covering both inpatient and outpatient care. During my days as faculty member of Gujarat Institute of Development Research (1985-96), then the Director gained access to filled-in paper questionnaires from the NSSO for Gujarat and Maharashtra for 1980-81 to undertake an in-depth analysis for better use of discarded resources. This paper, therefore, has enriched our analysis by comparing 1980-81 through 2014 data on morbidity and healthcare use in Western India covering about 35 years. The 1980-81 and 1986-87 surveys used 30 days recall period to report any illness or injury not-requiring hospitalisation; in the subsequent surveys of 1995-96, 2004, 2014, and 2017-18, however, this recall period was shortened to 15 days to match with most international morbidity surveys. In all these 5 surveys, a much longer recall period of 365 days was adopted for recording illnesses requiring hospitalisation with the intention to adequately capture such a rare event experienced by any members of the household. Further, certain important features on healthcare financing dimension on how people finance the cost of treatment were added from 1995-96 survey (Gumber and Berman 1997).

On the basis of recommendations made in the working paper at Harvard School of Public Health (Gumber and Berman 1997), several important modifications and new features were added to the 1995-96 questionnaire on healthcare utilisation. These were: (1) shortening of the recall period for morbidity from 30 to 15 days to match with international standard; added point prevalence of morbidity; (2) preventive and promotive health behaviour and knowledge including immunization (children and pregnant women), iodised salt, ORT (oral rehydration therapy), house insecticide spray, etc.; (3) insurance coverage (life, medical, accident); (4) expanding on items on medical costs; (5) accounting of various OOP expenses for direct and indirect costs (such as transport, lodging, attendant charges, medical appliances, etc.); (6) sources of financing healthcare costs and related indebtedness; (7) 


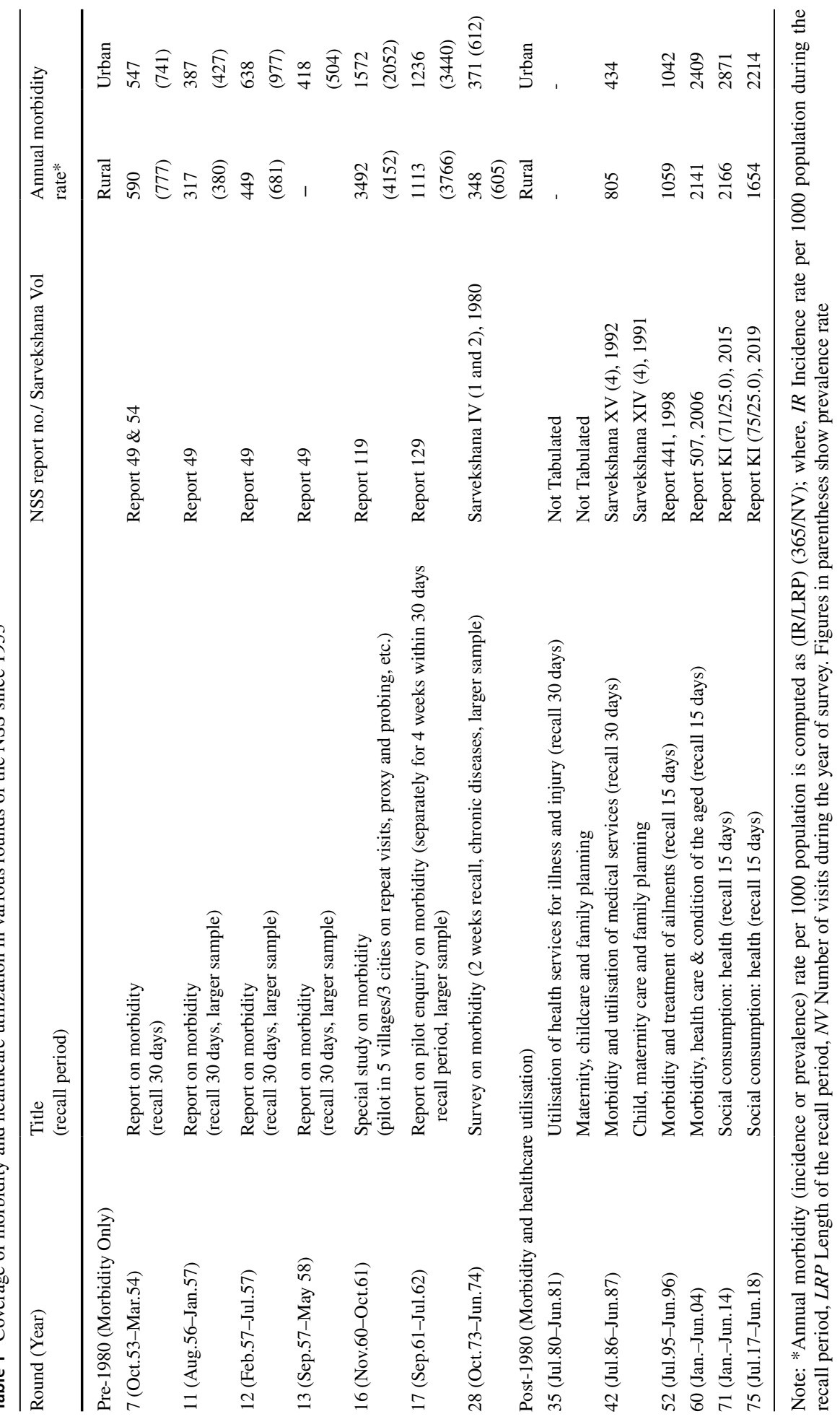


accounting for loss of work/income due to illness; and (8) modification in sampling design and use of an integrated questionnaire covering preventive, promotive and curative healthcare for 10 sampled households instead of three quota sampled questionnaires canvassed separately for Maternal and Child Health, Hospitalisation, and Ailments (Gumber 2016).

A comparison of absolute monetary values (e.g. expenditure on treatment) across different NSS rounds would be very misleading if not adjusted for rising prices overtime. In order to neutralise the effect of inflation on the cost of treatment over-time, a deflator based on the wholesale price index for pharmaceutical products was calculated. Thus, all overtime OOP expenditure data were presented at 1993-94 prices. This deflator instead based on the conventional consumer or wholesale price index for all commodities, mirrors much better the escalating cost of treatment currently faced by the people. It has been observed that the inflation of pharmaceutical products is higher as compared to all commodities. The wholesale price for pharmaceutical product is estimated to have increased by 318 per cent against 240 per cent for price of all commodities during the period 1994-95 to 2011-12 (computed from RBI report on Wholesale Price Index for various years under sub-category-Manufacture of Pharmaceuticals, Medicinal Chemical and Botanical Products). Since much of the recurring health expenditure is incurred on purchasing the required medicines as an inpatient or outpatient case, use of the price index for pharmaceutical products is more relevant for a discussion on rising healthcare expenditure in India than any other price index.

\section{Public and private healthcare providers}

Public health services play an important role in providing better and affordable access to the poor. Unless people have an alternative, they may be compelled to pay high prices or be forced to opt out of health services altogether (Sen et al. 2002). In a country where the private health expenditure contributes more than 70 per cent (remaining $30 \%$ by the Govt.), it is important to understand the share of public health providers in inpatient and outpatient care (Gumber 2002). The share of private (including not-for profit institutions) sector in healthcare provision is growing rapidly. The new private entrants are actively encouraged by the government through granting tax exemptions and subsidised land and capital for setting up hospitals. As there are no official sources of recording private health providers in terms of hospitals, nursing homes, and clinics; however, the NSS Enterprise Survey (2010-11) (Government of India 2015) has estimated 1.04 million private health enterprises in India (see Table 2). Study by Hooda (2015) highlighted that their number expanded considerably in the post-liberalization phase of the 1990s, which further accelerated exponentially in the 2000s specifically in urban India (the rural share in private health enterprises in 2010-11 was just 18 per cent).

The public health sector has also expanded over time; however, the expansion accelerated (in terms of a number of hospitals and beds) within the last decade. This was mainly driven to address globally sustainable development goals agenda in promoting institutional births and reduce maternal and neonatal mortalities. Some of these expansions are reflected in the improvement indicator of population served per hospital bed during 2004-2014. Interestingly, in contrast to the expansion of the private health sector in the 2000s which was dominant in urban areas, the expansion of the public health sector in rural areas has received a much fairer allocation. According to the National Health Profile compiled by the Ministry of Health and Family Welfare and presented in Table 2, during 2004-14 the 


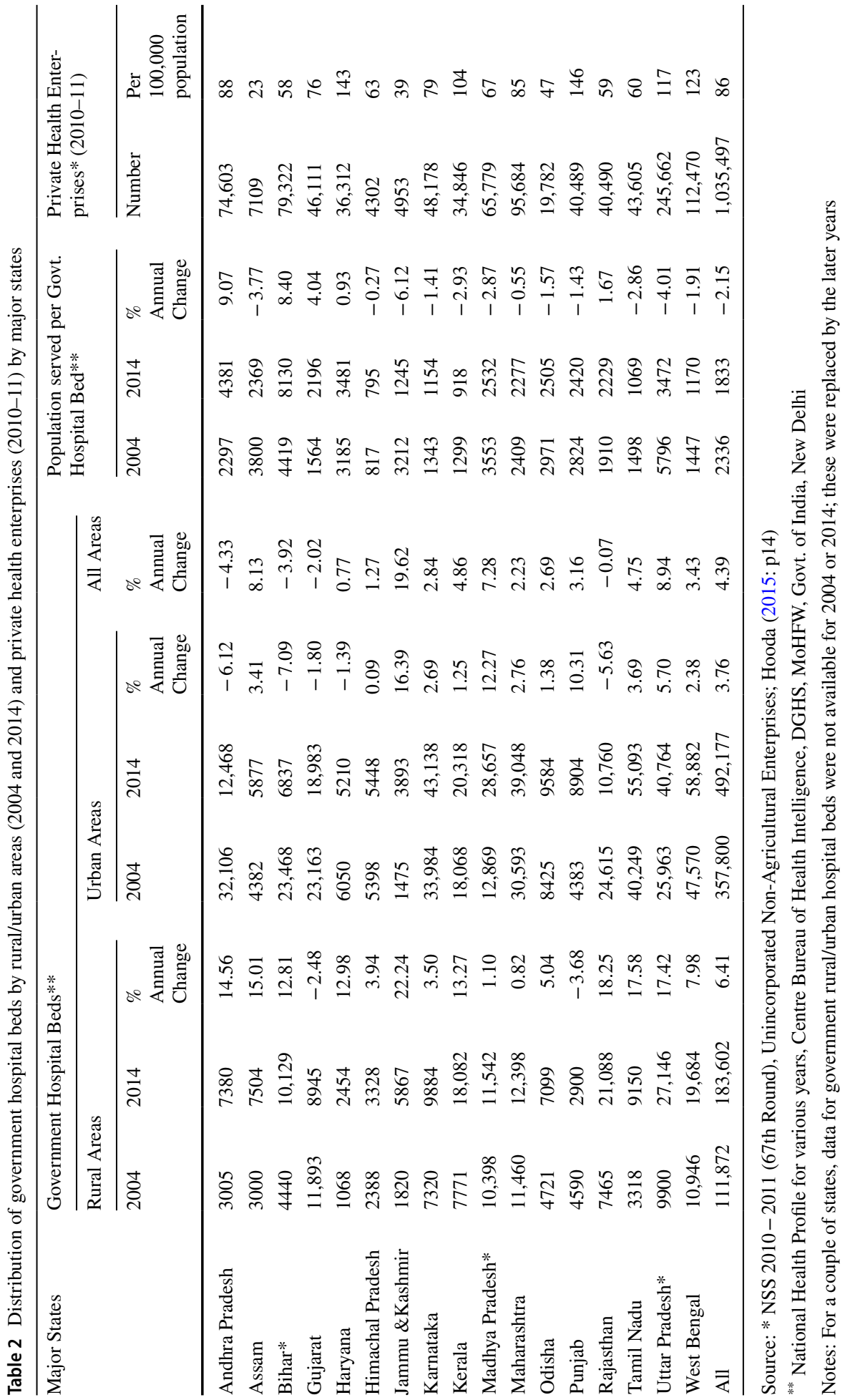


number of government hospital beds in rural areas, in fact, increased at a much faster pace from 111,872 to 183,602 (64\% rise) than in urban areas from 357,800 to 492,177 (38\% rise). Nevertheless, the pace of expansion of government hospital beds in rural areas varied considerably at state-level; the highest decadal growth was recorded in Jammu and Kashmir (222\%) which was followed by Rajasthan (182\%), Tamil Nadu (176\%), and Uttar Pradesh (172\%). On the contrary, the contraction in the number of rural hospital beds was recorded in Punjab and Gujarat during the same period. However, these results should be interpreted with caution due to misclassification/re-classification of some urban hospitals as rural hospitals over-time under the National Rural Health Mission funding and in some states classifying CHCs or up-graded PHCs under rural hospitals. That's how in several states including Bihar, Andhra Pradesh, and Rajasthan we have observed a negative or negligible growth rates in government hospital beds in urban areas during 2004-14.

The combined expansion of government rural and urban hospital beds during 2004-2014 was quite discernible in Jammu and Kashmir (196\%), Uttar Pradesh (89\%), Assam (81\%), and Madhya Pradesh (72\%). On the contrary, a contraction in the government hospital beds was recorded in Andhra Pradesh, Bihar, and Gujarat as a result population served per government hospital bed had gone up in these states during 2004-14. Overall, the government health infrastructure in terms of population served per hospital bed remained poor in Bihar, Andhra Pradesh and Uttar Pradesh in 2014 and was better served in Himachal Pradesh, Kerala, and West Bengal. From Fig. 1, which provides population served per (a) government hospital bed (2014) and (b) private health enterprise (2010-11), it is clear that both government and private health infrastructure are much below the national average for Maharashtra and Gujarat. Leaving aside hilly states (J\&K and Himachal), Kerala, Tamil Nadu, and Karnataka have much better supply of government health facilities and on the other Punjab, Haryana, and West Bengal have much better availability of private health facilities.

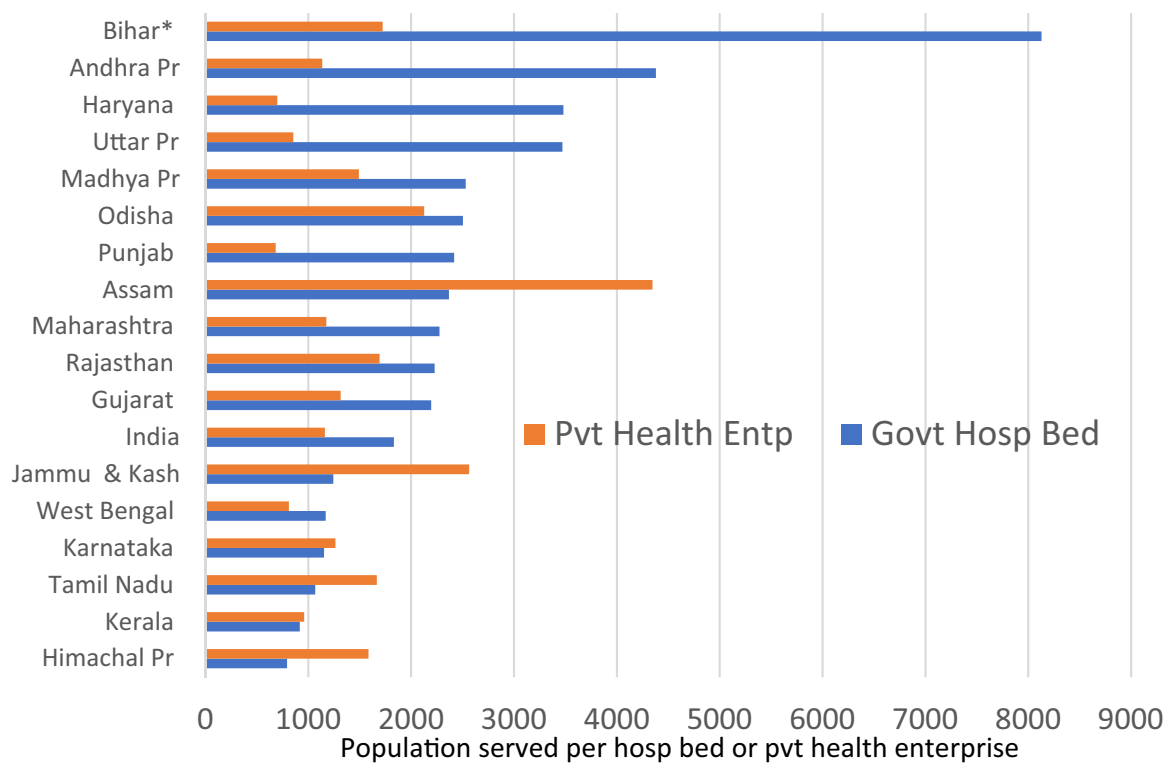

Fig. 1 Major states ranked on the basis of population served per government hospital bed with population served per private health enterprise 


\section{Morbidity pattern and health seeking behaviour}

The WHO has defined health as the state of physical and mental well-being, and any deviation from such state is to be considered as illness. Concepts and measurements of morbidity and utilisation of health services used during the various NSS rounds are discussed in detail elsewhere by Gumber and Berman (1997). To make a comparison of self-reported morbidity rate over the different NSS rounds with varying recall/reference period, the annual morbidity rates were computed and are presented in Fig. 2 for Gujarat and Maharashtra as well as for India and for two highest reporting states of Kerala and Tamil Nadu. It is evident that the morbidity rates were reported to be much lower during 1970 and 1980s (less than 1 episode per capita per year); from 1995-96 when the reference period was standardised to 15 days, the morbidity just touched 1 episode per capita mark; and in the subsequent round of 2004 it doubled to 2 episodes per capita in both rural and urban India. However, in 2014 this almost touched to 3 episodes per capita in urban India, whereas this remained around 2 episodes in rural India. In Fig. 2, India rates are depicted through bars and select states through line graph to improve visibility. Morbidity rates in both Gujarat and Maharashtra are matching with that for India. However, Kerala consistently reported the highest level of morbidity in both rural and urban areas in all the NSS rounds. Surprisingly, the morbidity rate in Kerala has risen exponentially during 2004 and 2014. The morbidity rates were marginally higher than the national average in Tamil Nadu until 2004. But by 2014, the rate in Tamil Nadu almost doubled than the national average. From the previous two NSS rounds, it is evident that illness rate in the population has risen and more significantly in the urban areas; Kerala and Tamil Nadu have reported exponential rise in morbidity rates (per capita annual episodes of 7.5 and 5, respectively). The morbidity levels in Gujarat and Maharashtra are just below the national average.

The decision to seek treatment for an ailment is influenced by both need/demand and supply factors; the former includes the person's socio-economic and demographic characteristics and the nature of ailment, and the latter describes an access and proximity to a medical facility. The percentage of illnesses treated by rural/urban areas and gender

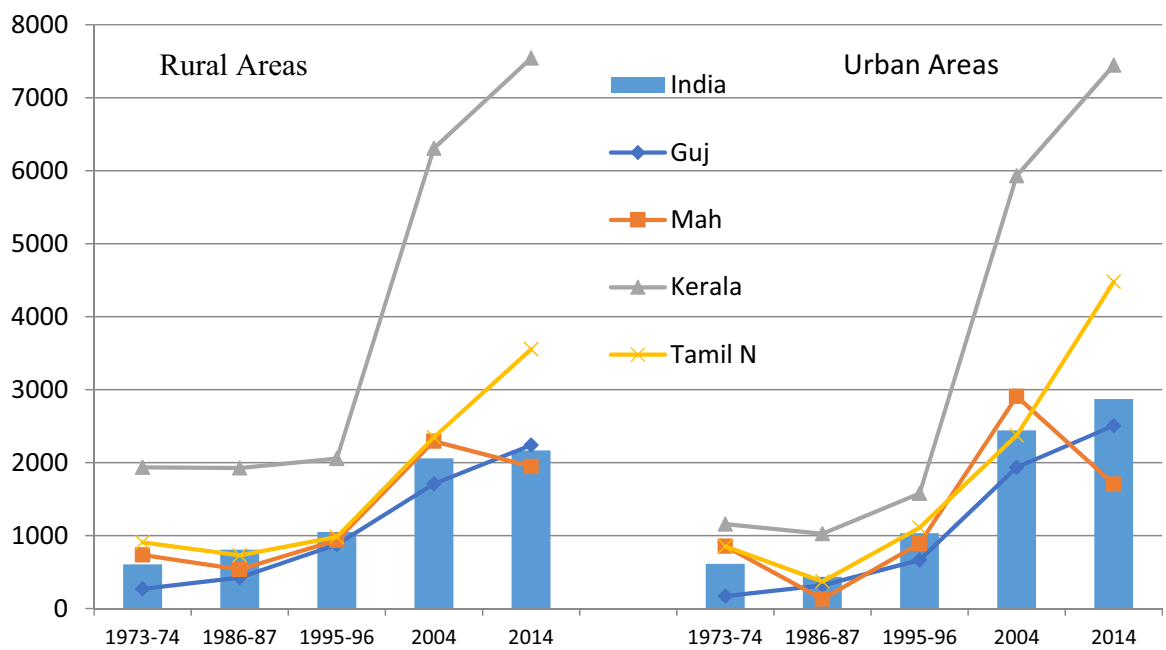

Fig. 2 Annual morbidity rate (per 1000 population) for select states, 1973-4 to 2014 
shows disparities in the health seeking behaviour in Gujarat and Maharashtra as well as all-India. Compared to rural areas the share of treated illnesses in urban areas for both males and females remained consistently higher in all the rounds thus clearly reflecting a better availability and proximity to health facilities in urban areas. At the national level, the rural-urban gap has narrowed down in 2014 as compared to 1986-87; the gender gap in favour of males which was distinct in the previous three rounds disappeared by 2014 (Fig. 3). Compared to the national average both Gujarat and Maharashtra have shown better health seeking behaviour by males as well as females over the four rounds particularly in urban areas. However, in 2014 the gender gap in favour of males was notable in rural Gujarat and in favour of females in urban Maharashtra. The gender inequities in seeking treatment in rural areas were also observed persistently over the rounds in several major states (for details see: Gumber et al. 2017).

The NSS surveys had sought responses on the underlying reasons for not seeking treatment for their illnesses, which could be due to: (a) no nearby medical facility; (b) lack of faith; (c) long waiting; (d) financial reasons; (e) ailment not considered serious; and (f) all other reasons. In both rural and urban India, $15.4 \%$ and $1.3 \%$ of responses respectively related to lack of medical facility as the reason for non-treatment in 2014 (Fig. 4). The accessibility to a medical facility in rural areas is a cause of concern. This indicates that a certain section of the population is not having a proximate access to basic primary healthcare facilities. The dominant reason for not seeking treatment was "ailment not considered serious" by both rural and urban population in all the NSS rounds for Gujarat, Maharashtra as well as India. However, in rural Maharashtra the financial reasons for not seeking treatment were notable in 2004. The affordability of treatment is always a decisive factor for the poor and vulnerable people for not seeking medical help. An earlier study by Gumber (1997) reported that nearly half of the people in the bottom expenditure quintile forego medical treatment for financial reasons. Financial reasons were the topmost reason for not accessing treatment in some of the poorer states. Finally, the state-level data show that there was a significant positive correlation between the proportions of untreated illnesses for rural areas with those in urban areas; and overtime the size of correlation coefficient has increased from 0.643 in 2004 to 0.815 in 2014 . This demonstrates that socio-economic

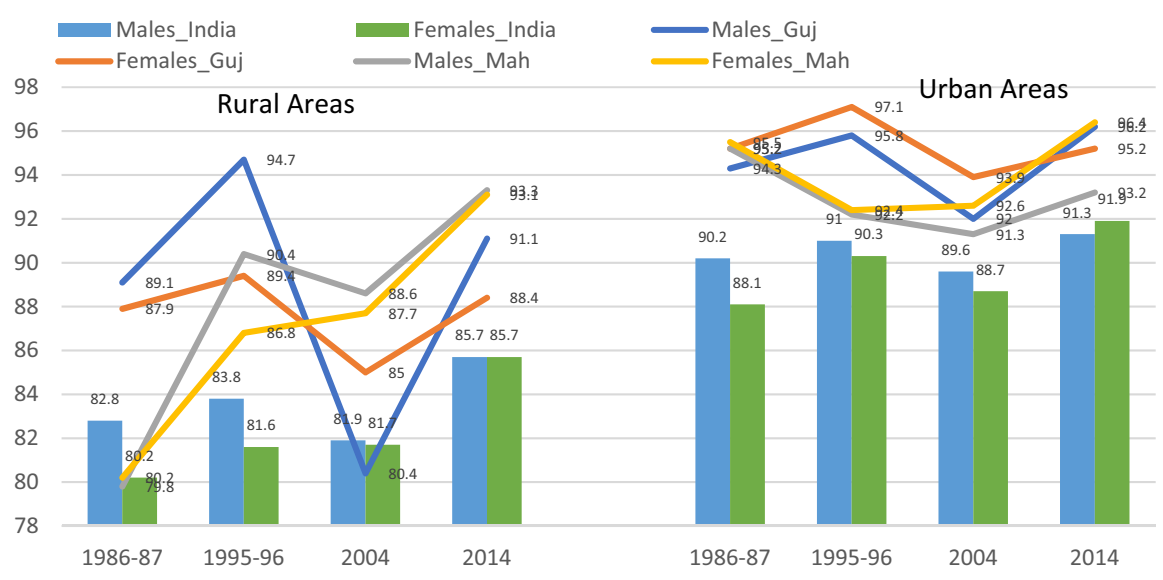

Fig. 3 Share of treated illnesses by gender in rural and urban areas, 1986-87 to 2014 


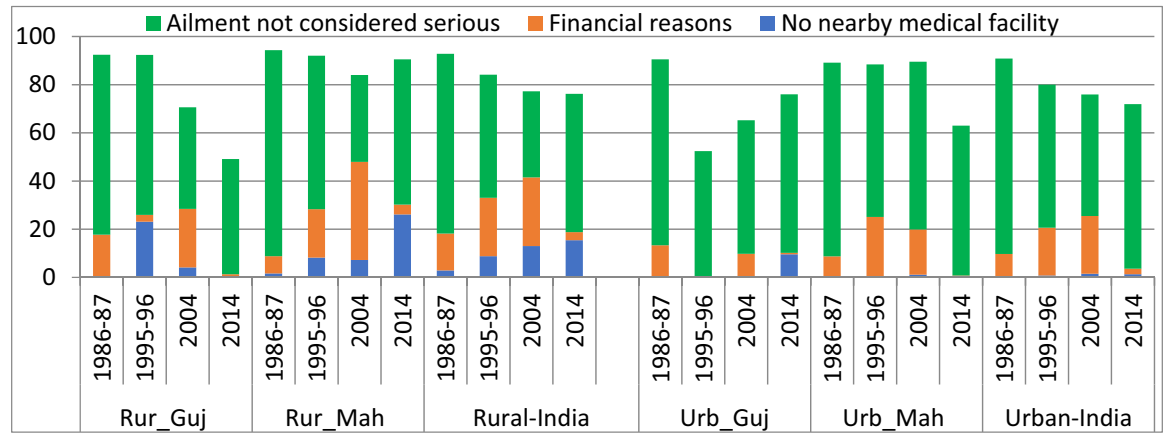

Fig. 4 Three important reasons for not seeking treatment, 1986-87 to 2014

environment and health infrastructure at state-level impact health seeking behaviour equally between rural and urban residents.

\section{Reliance on public services for curative care}

As discussed in the previous section on the rapid growth of private healthcare providers over the last three decades, the resultant impact has been observed on the shrinkage of the public sector share in dealing with both inpatient and outpatient care. At national level, the share of public providers in inpatient care for rural residents though declined from $59.7 \%$ in $1986-87$ to $41.7 \%$ in 2004, but recorded improvement to $50.3 \%$ in 2014 (Fig. 5). During 1986-2014, the decline in the share of public providers for rural residents is relatively less, compared to the decline witnessed for urban residents at all-India level. The share of public providers in urban India which was $60.3 \%$ in $1986-87$ declined to $35.5 \%$ in 2014 . If we consider only 2004-2014 period, in contrast to increase in utilisation for rural residents, the share of public providers declined marginally from $38.2 \%$ to $35.5 \%$ for urban residents. This declining effect was also seen in Gujarat and Maharashtra since 1980-81. During 1980-81, the public sector played a dominant role in inpatient care for both rural and urban residents of Gujarat and Maharashtra. But its share declined considerably since

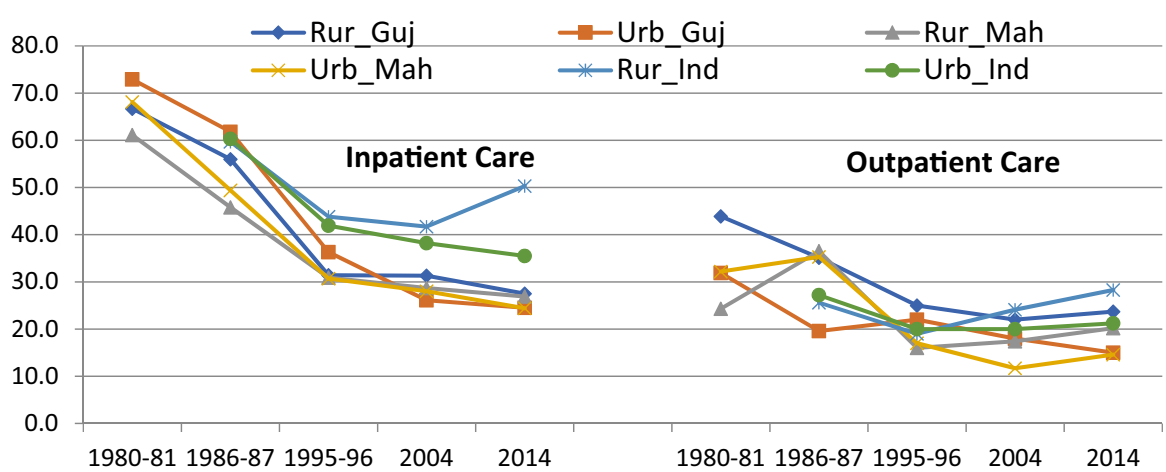

Fig. 5 Share of public providers for inpatient and outpatient care, 1980-81 to 2014 
1986-87; the decline was much sharper in urban areas for both Gujarat and Maharashtra (72.9\% to $24.5 \%$ for Gujarat and from $68.1 \%$ to $24.4 \%$ for Maharashtra during $1980-81$ to 2014). This sharper decline is quite evident due to faster expansion for-profit private providers in cities. Hooda (2015) observed that expansion of private health enterprises at state-level was negatively correlated with the reliance on public hospitals; we also found a negative correlation between number of private enterprises per 100,000 population (as shown in Table 2) with percentage share of public providers in inpatient care $(-0.536$ for 2004 and -0.593 for 2014) for 17 major states.

For outpatient care the scenario of public providers is very dismal; at national level their share in outpatient care in 2014 (28.3\% for rural and $21.2 \%$ for urban residents) was much lower than that for inpatient care $(50.3 \%$ and $35.5 \%$ for rural and urban, respectively). Interestingly, the share of public providers in outpatient care for rural India has shown some improvement in 2014 compared to 1986-87; but for urban India it remained stagnant since 1986-87 at around 20-21\% (Fig. 5). In both rural and urban Gujarat and Maharashtra the reliance on public providers in 2014 was much lower than the national average. During 1980-81 to 2014 the decline in the share of public provider in outpatient care was also observed in both rural and urban areas of Gujarat and Maharashtra; however, the decline was much sharper and consistent in rural Gujarat than in rural Maharashtra. This scenario for other Indian major states is quite different. For instance, in 2014 people resident in rural or urban or both areas in hilly states of India (Assam, Himachal Pradesh, and Jammu $\&$ Kashmir) and in Odisha relied heavily on public providers for outpatient care. Further, expansion in government health infrastructure at state-level during 2004-14 has also shown an improvement in the uptake of outpatient services in select states. A significant negative correlation was found between population served by a government hospital bed in 2014 (as shown in Table 2) with percentage share of public providers in outpatient care for urban areas $(-0.521)$ for 17 major states.

An inter-state analysis shows that the expansion in availability of government hospital beds over time especially in rural areas has directly altered the healthcare utilisation by rural residents in favour of public providers. Gumber et al. (2017) found that the interstate correlation coefficient between population served per government hospital bed with percentage share of treated illnesses in 2014 was highly significant $(-0.720$ for rural and -0.611 for urban areas). Further, the population served per government hospital bed was also significantly correlated (-0.619) with percentage change in share of treated illnesses between 2004 and 2014 in rural areas; thus, signifying improvement in the access to government facilities in a state leads to better health seeking behaviour for their rural residents. The improvement in government health infrastructure also led to increase in reliance by rural residents on public facilities for inpatient care. Significant positive correlation coefficients at state-level were found between percentage share of public providers for inpatient care and changes in number of government hospital beds during 2004-14 (0.532 for 2004; 0.500 for 2014).

The reliance on public providers for treatment specially by the poor and vulnerable groups also depend on both quality and extent of free services. The share of private providers in the provision of free health services for both inpatient and outpatient care is negligible. Therefore, those who have been treated in government facilities also received free treatment (an eligibility criterion was introduced in 2000s). To capture this aspect, Fig. 6 displays the percentage of patients who received free hospital beds (as a proxy for free inpatient care) and free medicine (as a proxy for free outpatient care).

Similar to the share of public providers, free provision of bed in inpatient care has declined from $60.7 \%$ in $1986-87$ to $37 \%$ in 2004 and then improved to $47.3 \%$ in 2014 for 


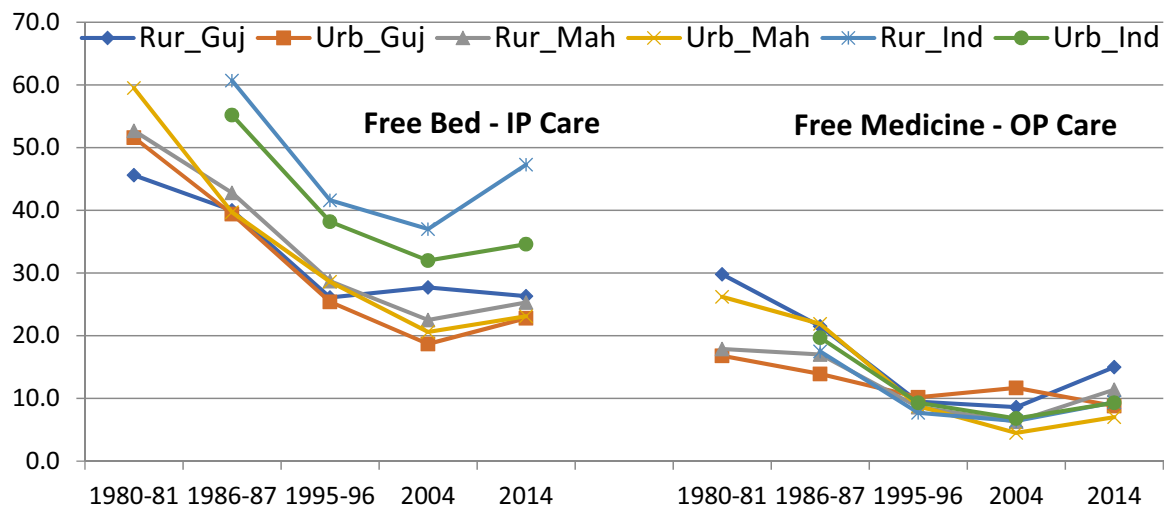

Fig. 6 Share of free hospital bed (inpatient) and free medicine (outpatient), 1980-81 to 2014

rural India. A similar trend is seen in urban India as well but at a lesser magnitude. Nevertheless, as noted by Sundararaman and Muraleedharan (2015), this trend indicates the pro-poor nature of public health care use. In Gujarat and Maharashtra, the receipt of free inpatient care for both rural and urban population diminished at much faster rate than the national average and currently stands much lower than the national average. More than $50 \%$ population in Gujarat and Maharashtra received free inpatient care in 1980-81 which declined to about $25 \%$ in 2014 -almost a half of the national level. Unlike Gujarat and Maharashtra, a majority of rural residents in several states has continued to receive free inpatient care.

Regular purchasing of medicines particularly for chronic conditions for many occasions become unaffordable to poor and sometime makes people vulnerable to debt. Free medicine provisioning would reduce this vulnerability considerably. At the national level, provision of free medicines during 1986-87 to 2014 has declined to under 10\% for both rural and urban population. Only in Tamil Nadu and Rajasthan which adopted subsidised medicine programme, the percentage of patients reporting free medicines in 2014 is high for both rural and urban populations. The scenario for rural residents of Gujarat and Maharashtra for free outpatient care in 2014 is found to be better and for urban residents worse than the national level. Both Gujarat and Maharashtra have shown decline in free outpatient care since 1980-81 and the decline was greater for rural residents. Berman et al. (2010) has pointed out that the OOP expenditure to meet the healthcare costs, particularly, arising from the non-availability of free medicines would impoverish the poor further.

\section{Cost and burden of treatment}

Before discussing the average cost of treatment in terms of OOP expenditure incurred by the patients on inpatient and outpatient care, we found the cost of treatment by private provider is greater than the public provider. Beside accessibility, price is the most important consideration in choosing the public over the private provider, especially, for the treatment of chronic and catastrophic conditions. According to the National Health Policy 2015, the private sector handles for $60 \%$ of inpatient and $80 \%$ of outpatient cases. The private-public cost ratios for inpatient care for various years (in Fig. 7) are greater than 1 thus indicating 


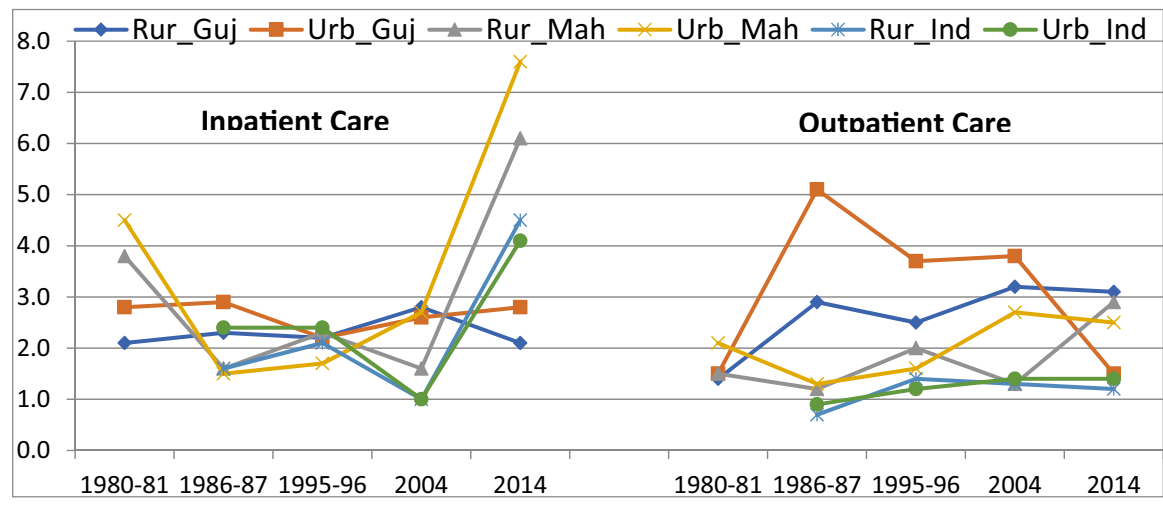

Fig. 7 Private-public treatment cost ratios for inpatient and outpatient care, 1980-81 to 2014

private hospitals are much costlier than the public hospitals and overtime, at the national level, the cost almost tripled (from 1.6 to 4.5) for rural residents and doubled (from 2.4 to 4.1) for urban residents between 1986-87 and 2014. However, during 2004 and 2014 the difference in cost of treatment between private and public hospitals has narrowed down. This could be due to reduction in charges by the private providers owing to severe competition and imposing of user charges by government hospitals in several states including Gujarat and Maharashtra to finance services for the poor. In Gujarat, the cost-ratio for both rural and urban residents hovered around 2 to 3 times during 1980-81 and 2014, but in Maharashtra this ratio shot up to 6.1 for rural and 7.6 for urban residents by 2014; thus, indicating an exorbitant cost to treat in a private hospital in Urban Maharashtra.

It is found that such cost ratio for outpatient care is not as wide as that for the inpatient care for both rural and urban populations. Remarkably, during 1986-87 the private providers were found to be cheaper than public providers (by $30 \%$ for rural and $10 \%$ for urban) in handling outpatient cases at the national level. Since then, the private provider turned expensive and more so in urban India. Surprisingly, in 2014 the cost ratios for rural residents in Gujarat and Maharashtra are higher when compared with urban residents; further rural residents in both states experienced increasing cost ratios during 1980-81 to 2014 . These facts clearly reflect that rural residents compared to their urban counterparts are discriminated (probably due to lack of knowledge) by paying more to private providers for their outpatient treatment.

The time trend in overall total OOP expenditure on treatment (both direct and indirect medical payments) at constant prices (of 1993-94) per hospitalisation episode is shown in Fig. 8. At the national level, in 2014 it was Rs.3965 for rural and Rs.7109 for urban residents; such rural-urban gap was expected due to differences in the cost of living and the type of care sought. Overtime, the cost of hospitalized treatment in real terms at the national level has increased for both rural and urban populations; the latter experienced much higher increase than the former (Rs.1605-Rs.3965 for rural with 5.3\% annual growth rate and Rs.2227 to Rs.7109 for urban with 7.8\% AGR [Annual Growth Rate] during 1986-2014). Gujarat and Maharashtra have also shown a rising trend, higher than the allIndia. During 1980-81 to 2014 the hospitalisation cost in Gujarat increased from Rs.1366 to Rs.3852 for rural residents with 5.4\% AGR and from Rs.1453 to Rs.5678 for urban with $8.6 \%$ AGR). The corresponding figures for Maharashtra were Rs.1016 to Rs.5369 


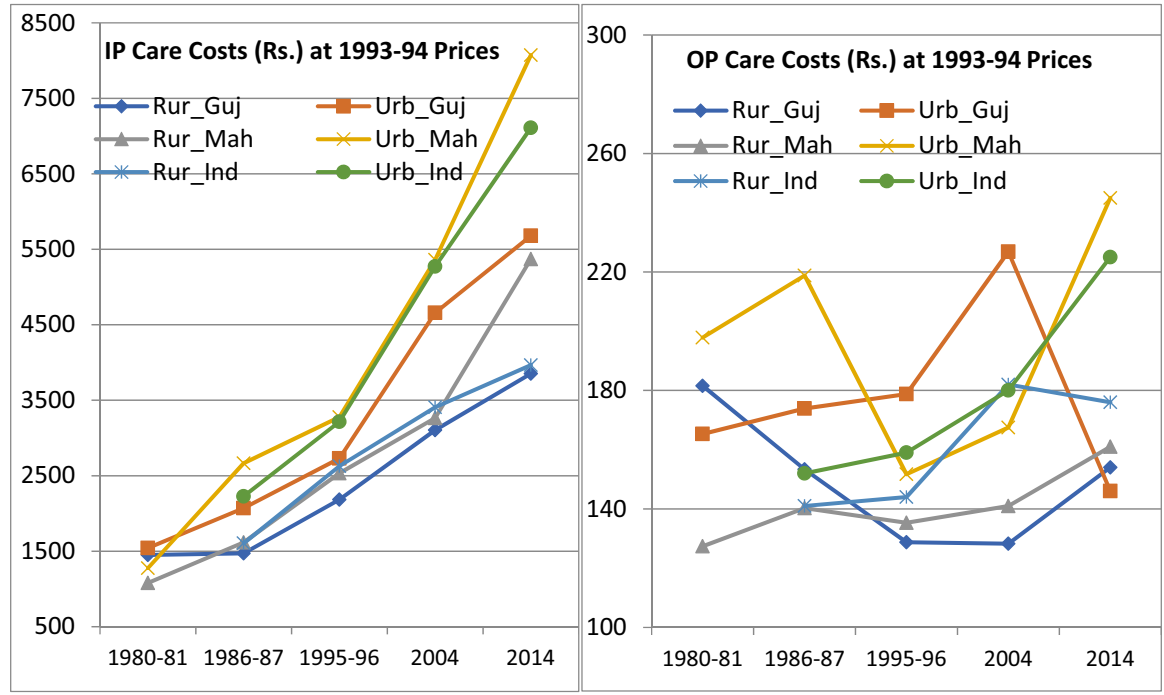

Fig. 8 Inpatient and outpatient care cost, 1980-81 to 2014 (in Rs. at 1993-94 prices)

for rural residents with 12.6\% AGR, and Rs.1203 to Rs.8072 for urban with 16.8\% AGR. This clearly reveals an exponential increase in the real cost of inpatient care in Maharashtra (which was twice faster than the national average). An inter-state analysis shows that Kerala, Tamil Nadu, and West Bengal also reported the highest growth rate $(22.1 \%, 17.3 \%$ and $11.3 \%$ AGR, respectively, during 1986-2014) in inpatient costs for rural residents; and Tamil Nadu, Haryana, Andhra Pradesh, Madhya Pradesh, Assam, and Kerala had recorded very high AGR of $19 \%$ to $21 \%$ (Gumber et al. 2017).

On the other hand, compared to inpatient care the real cost of outpatient care has not grown much (Fig. 8). At the national level for rural residents this has increased from Rs.141 (1986-87) to Rs.182 (2004) and then stagnant at Rs.176 (in 2014); however, for urban residents it has consistently increased from Rs.152 in 1986-87 to Rs.225 in 2014. At all-India level, the cost of outpatient care grew by $0.9 \%$ AGR for rural residents and $1.7 \%$ AGR for urban residents. In Gujarat the real cost of outpatient care in fact decreased from Rs.171 in 1980-81 to Rs.154 in 2014 with-0.3\% AGR for rural residents and the respective figures for urban residents were Rs. 156 to Rs.146 with-0.2\% AGR during the same period. In contrast, Maharashtra has followed the national trend; the real cost of outpatient care for rural residents increased from Rs.120 to Rs.161 during 1980-2014 with 1.0\% AGR and from Rs.186 to Rs.245 with 0.9\% AGR for urban residents during 1980-2004. A wave pattern (increase or decrease) was seen at the national as well as in Gujarat and Maharashtra in the intervening period.

Such mounting rise in the cost of treatment particularly for inpatient care over 35 years deserve a separate analysis in order to understand whether the bottom quintile of households (Poorest) on their monthly per capita expenditure (MPCE) have faced similar or lower hospitalisation costs as compared to the average households over time. Figure 9 shows that bottom $20 \%$ of households have also faced steep rise in hospitalisation cost (at constant prices of 1993-94) but only during 2004 and 2014 in both Gujarat and Maharashtra. Further, in both states the poor in rural areas compared to their urban counterparts faced much steeper rise in hospitalisation cost in 2014 over 2004. Overall, the poor have incurred lower 
OOP expenditure on hospitalisation, but this does not affirm their capacity to pay as previous studies have shown that an episode of hospitalisation impoverishes at least one-thirds of households (Gumber 2000; Gumber and Kulkarni 2000; World Bank 2001). This issue is examined further in the next section on how much the health insurance mechanism have provided financial protection to the poor against hospitalisation expenses (Fig. 10).

\section{Financial protection for hospitalisation for poor/non-poor}

Since 1995-96 survey a question on health insurance enrolment was introduced, whilst asking for any amount of health insurance premium paid by the household during the last 365 days. At the national level, only $0.5 \%$ of households reported such enrolment in $1995-96$, which improved to $1.9 \%$ in 2004 , and further to $6.1 \%$ in 2014 . The lowcost hospitalisation insurance scheme by the government (Rashtriya Swasthya Bima Yojana-RSBY) was introduced in 2008 in which the below poverty line (BPL) households automatically get qualified to enrol without paying any charges. Later on, few state governments introduced similar schemes for the BPL households as well. Therefore, in the 2014 survey an additional question was asked to each member of the household for enrolment to the government-funded health insurance schemes including RSBY or private health insurance. Thus, from this survey a household 'health insurance coverage' (HIC) variable designating where at least one member has been enrolled to any government or private health insurance scheme (irrespective of whether paid any annual premium) was computed.

The analysis for 2014 shows that $17 \%$ of rural and $22 \%$ of urban households are covered by some health insurance scheme at the national level; a larger coverage was noticed among the top economic quintile (categorised by Monthly Per Capita Expenditure-MPCE). The top quintile has $28 \%$ vs. $13 \%$ HIC for the bottom quintile-the inequity ratio between the top and bottom quintile is 2.2 (Table 3). For Gujarat the HIC was 14\% for rural and 19\% for urban households; for Maharashtra these figures were much lower, $3 \%$ for rural and $17 \%$ for urban households. In terms of equity, the HIC in Gujarat for the top quintile was $24 \%$ vs $15 \%$ for the bottom quintile and their inequity ratio is 1.7 . The respective figures of Maharashtra were $25 \%$ vs $<1 \%$ with inequity ratio as high as 29.4 . Few other states have also shown a much higher inequity in HIC (for instance, Haryana 684.8, Punjab 49.7, and

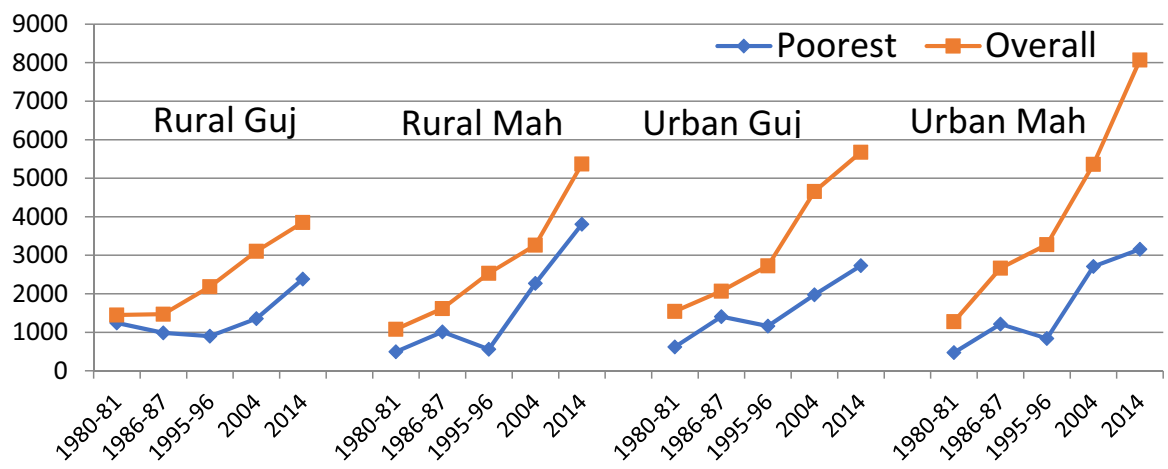

Fig. 9 Hospitalisation cost for the poor and general households (in Rs. at 1993-94 prices) 
Table 3 Health insurance coverage by MPCE quintile for major states, 2014 (\% of households)

\begin{tabular}{lllllllllll}
\hline Major States & Rural & Urban & All & \multicolumn{2}{l}{ MPCE Quintile } & & & & \\
\cline { 6 - 11 } & & & & & Bottom & 2nd & 3rd & 4 th & Top & (Top/ \\
& & & & & & & & & Bottom) \\
\hline Andhra Pradesh & 72.93 & 50.42 & 65.74 & 54.08 & 68.39 & 72.80 & 72.15 & 49.20 & 0.91 \\
Assam & 2.26 & 12.99 & 3.70 & 2.64 & 2.25 & 1.39 & 8.55 & 9.20 & 3.49 \\
Bihar & 7.15 & 5.41 & 6.97 & 8.86 & 6.95 & 4.60 & 4.51 & 4.71 & 0.53 \\
Gujarat & 13.77 & 18.83 & 15.98 & 15.06 & 11.47 & 10.47 & 13.47 & 25.42 & 1.69 \\
Haryana & 3.00 & 19.75 & 8.88 & 0.03 & 1.92 & 5.17 & 8.19 & 21.70 & 684.84 \\
Himachal Pradesh & 13.13 & 16.58 & 13.57 & 7.23 & 7.92 & 8.33 & 15.12 & 23.26 & 3.22 \\
Jammu \& Kashmir & 9.04 & 18.24 & 11.11 & 7.57 & 14.44 & 7.93 & 4.24 & 20.67 & 2.73 \\
Karnataka & 9.92 & 20.26 & 14.16 & 6.23 & 6.57 & 8.49 & 14.74 & 34.17 & 5.49 \\
Kerala & 51.15 & 42.54 & 47.22 & 79.18 & 58.56 & 51.75 & 49.23 & 41.97 & 0.53 \\
Madhya Pradesh & 0.44 & 8.68 & 2.61 & 0.69 & 0.19 & 2.52 & 4.72 & 13.42 & 19.41 \\
Maharashtra & 3.39 & 17.39 & 9.87 & 0.84 & 2.84 & 1.81 & 5.31 & 24.75 & 29.41 \\
Odisha & 23.70 & 13.99 & 21.92 & 30.10 & 16.32 & 11.10 & 10.53 & 19.05 & 0.63 \\
Punjab & 4.30 & 11.33 & 7.07 & 0.23 & 5.11 & 3.75 & 4.58 & 11.31 & 49.69 \\
Rajasthan & 24.39 & 29.38 & 25.75 & 39.93 & 21.36 & 18.75 & 18.56 & 34.68 & 0.87 \\
Tamil Nadu & 19.34 & 26.29 & 22.87 & 6.19 & 14.52 & 19.52 & 22.65 & 32.20 & 5.20 \\
Uttar Pradesh & 4.90 & 8.87 & 5.86 & 4.93 & 6.42 & 3.04 & 3.16 & 16.34 & 3.31 \\
West Bengal & 16.46 & 23.01 & 18.54 & 13.87 & 18.13 & 18.73 & 13.08 & 32.71 & 2.36 \\
All & 17.03 & 21.84 & 18.60 & 12.68 & 13.91 & 17.83 & 21.19 & 28.21 & 2.22 \\
\hline
\end{tabular}

Madhya Pradesh 19.1); on the contrary, the highly equitable and pro-poor HIC (i.e. with ratio < 1) states were Andhra Pradesh, Kerala, Odisha, and Rajasthan (Gumber et al. 2017).

The important question to answer is how much the financial protection is received for a hospitalisation episode by the poor and non-poor households. This is demonstrated by comparing the mean of the net hospitalisation expenses (after deducting for reimbursement amount) between households having and not having HIC (Fig. 10). Surprisingly, at the all-India level, the insured household on average had reported higher hospitalisation expenses (Rs.17261 vs. Rs.15773) than the non-insured households; such differential was much higher for urban households. A miniscule sum of relief was observed only for the rural households (Rs.12908 vs. Rs.13396), amounting 3.8 per cent lower expenses for the insured ones. However, among BPL households the hospitalisation expenses were about $15 \%$ lower if they had health insurance coverage (Rs.8568 vs. Rs.9878); this proportion goes up to $20 \%$ for BPL households in rural India and to $26 \%$ if belonged to the bottom MPCE quintile. This clearly reflects that health insurance has provided a marginal financial protection to BPL households and especially to those living in rural India.

Compared to the national average, a much higher hospitalisation expenses by the insured households in both Gujarat and Maharashtra were reported. These were twice higher for the insured Rs.24915 vs. Rs.13234 for the non-insured in Gujarat and for Maharashtra insured Rs.40058 vs. Rs.20021 for the non-insured (Fig. 10). An inter-state analysis shows that in Haryana, Maharashtra, Himachal Pradesh, and Assam the insured households end-up paying almost doubled the hospitalisation expenses when compared with their noninsured counterparts. Leaving aside Kerala (where insured households have paid just half 


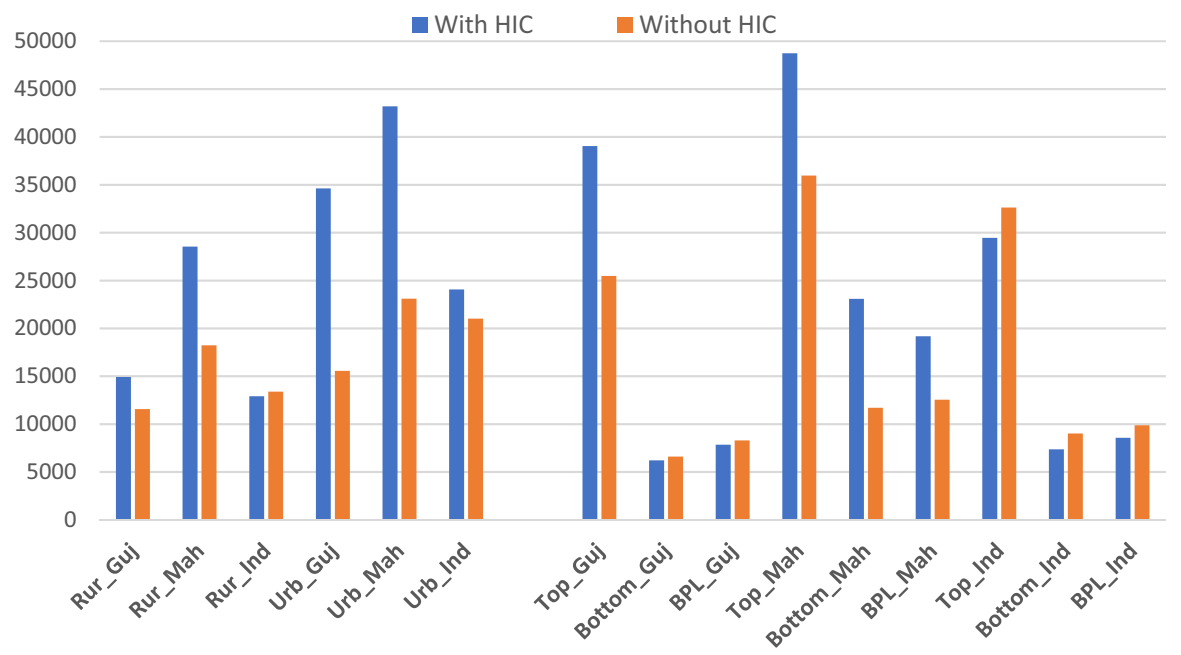

Fig. 10 Net hospitalisation cost for with and without health insurance coverage by rural/urban and income groups (Top and Bottom quintiles, BPL), 2014

of the cost of the non-insured), this clearly reflects widespread prevalence of moral hazard and insurance collusion in India (see Table 4).

However, a scenario appears to be less miserable if we look at the poor households. The insured BPL households in Gujarat paid a little lower amount as compared to the non-insured (Rs.7842 vs Rs.8296), on the contrary BPL households in Maharashtra have paid much higher amount (Rs.19180 vs Rs.12552) than the non-insured. Tables 3 and 4, together highlight the fact that states which had high level of insurance coverage for BPL households (Andhra Pradesh, Kerala, Odisha, and Rajasthan) have also reported relatively a much lower cost of hospitalisation for their insured vs. non-insured BPL households. These percentages were lower by 84.4 for Kerala, 57.7 for Odisha, 28.5 for Andhra Pradesh and 27.9 for Rajasthan. Interestingly, West Bengal had also reported lower hospitalisation cost by $41.6 \%$ for their insured BPL households (61.6\% for Madhya Pradesh was based on only 8 cases of insured BPL households). The situation for Assam, Punjab, Himachal Pradesh, Maharashtra, and Haryana was much worse where the insured BPL households had reported a much higher hospitalisation expenses than their non-insured counterparts.

\section{Conclusion}

In order to attain the UHC goal that 'all people and communities receive the quality health services they need without financial hardship' this paper has primarily aimed to make an assessment on each of these three UHC pillars, i.e. access, quality, and financial protection received for the treatment of ill-health by residents of Gujarat and Maharashtra as well as of whole India. In this paper, we have analysed data from five NSS Rounds (1980-81 through 2014) on morbidity and healthcare utilisation for Western India, whilst focusing on (a) morbidity pattern and trends in health seeking behaviour, (b) reasons for not accessing 


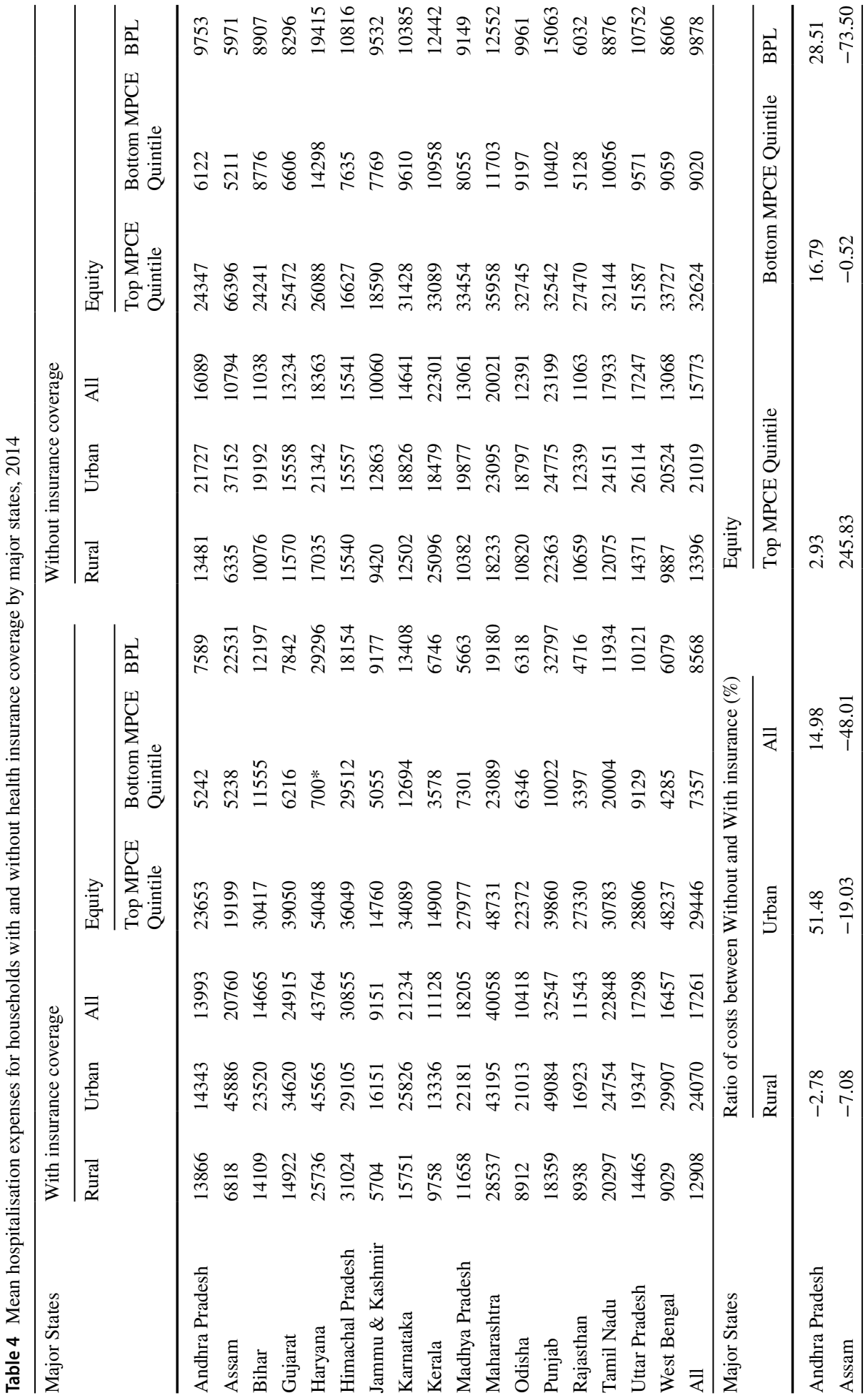




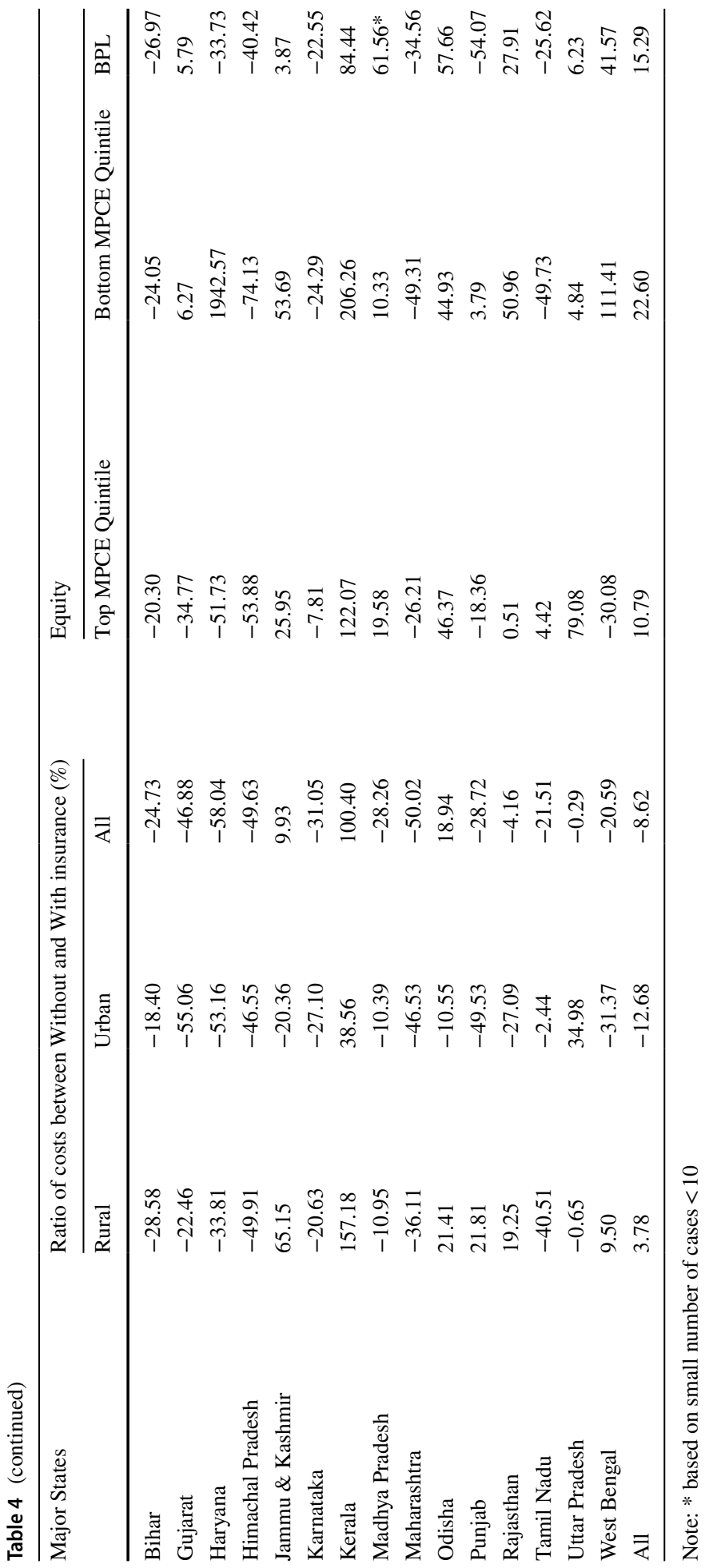


healthcare, (b) reliance on government health providers, (d) cost and burden of treatment, and (e) health insurance coverage and financial protection to the poor.

Our overall observation is that the public health providers played a major role in meeting healthcare needs in India in 1986-87. But the role is currently dwindling. Though several states have attempted to restore the public provision of healthcare by 2004, the gap seems to have widened by 2014 . Reliance on public health services is now restricted to $50 \%$ for rural residents and about $35 \%$ for urban residents in 2014 . We observe that while a majority of men and women sought treatment for their illnesses, the percentage of people reporting lack of access to the medical facility is more for rural than for urban populations indicating the urban-centric position of health providers and the public healthcare needs. At the same time the percentage of people reporting illnesses not serious enough requiring treatment has declined over the survey periods, indicating better health seeking behaviour of people in both rural and urban areas. The increase in availability of government hospital beds during the last decade particularly in rural areas considerably improved their health seeking behaviour. With the increasing level of morbidity in the country over time, a better public health provision would bring down significantly the loss of workdays due to illness and thereby increase the income/livelihood opportunities and reduce the vulnerability of rural residents as well as the poor.

Over the years, especially in the post-liberalization phase, the government has also promoted private health providers through a variety of schemes to meet the growing healthcare demand. The massive expansion of private providers since 2000s has no doubt reduced reliance on public providers for outpatient care. But they were not widely successful in reducing reliance on public providers for inpatient care because of cost consideration. Throughout the country, the cost of private health provision for hospitalisation has remained substantially high as compared to the public provision. We do observe a progressive reduction in the gap between public and private providers with respect to the cost of providing treatment indicating the rising cost of treatment in a public health facility. This could partly be due to the provision of care to critical patients as well as brought into A\&E department which the private sector are reluctant to handle.

There is an improvement in the utilisation of public health facilities for inpatient care especially by rural population in different states which are directly associated with the expansion of government health infrastructure during the last decade. Some of these health infrastructure expansions are attributable to initiatives of financing undertaken under the National Rural Health Mission. However, we observe a steep reduction in the percentage of people getting free beds and medicines (in several states including Gujarat) which needs to be addressed. The limited budgets of the state governments can be effectively utilised if the state governments strictly follow an essential drug list and purchase the generic drugs through pooled procurement system. Recently the central government's two initiatives to get the prescriptions done only in generic names and to open a janaushadhi (affordable medicine price) store in every district hospital has been expanding its coverage; this would definitely provide tremendous relief to people having chronic and long-term conditions and reduce considerably the OOP expenditure for the consumers.

The analysis of health insurance coverage and financial risk protection over various NSS rounds was limited due to the type of questions on health insurance included in the questionnaire including the responses for the clubbed categories of various government health protection schemes such as RSBY. Despite this fact, NSS 2014 data indicate that the targeted health insurance coverage, in order to provide effective financial protection to the poor and thus to meet catastrophic healthcare expenses, has remained limited to certain states. While Andhra Pradesh, Kerala, and Rajasthan may be labelled as 'pro-poor 
health insurance coverage' states, the situation was miserable (i.e. enrolment in favour of better-off class) in Madhya Pradesh, Assam, Punjab, and Uttar Pradesh. Thus, for a majority of states including economically prosperous states of Punjab, Haryana, Maharashtra, and Gujarat the provision and implementation of effective health insurance coverage to the poor and vulnerable population particularly engaged in the informal sector remains a huge task (Gumber 2000; Gumber and Kulkarni 2000) and poses a big challenge to achieve the UHC goal.

Indian Government recently has taken-up an exceptional healthcare and insurance initiative for the expanding Indian middle class, Aayushman Bharat Yojana (ABY) which also empanels private hospitals to cater to secondary and tertiary healthcare services. Often, statistics on healthcare services exclude the private healthcare infrastructure and staff which are now a part of the ABY. This will reduce the burden of healthcare on government alone, while providing an assurance for its credibility. A large number of private hospitals are empanelled under the said scheme, which takes care of the supply side in terms of the scale of infrastructure as well as medical and paramedical staff. However, the issue related to national schemes (RSBY and ABY) is in regard to 'effective' implementation by the state governments who already have their own pro-poor target-health insurance schemes. The main challenges are in improving the physical infrastructure of the public hospitals, continuum skills development of the healthcare professionals, and cost-effective management of medical and other logistic resources that would facilitate better access to healthcare by the poor and middle class particularly resident in rural India.

Acknowledgements This paper is devoted to my PhD Supervisor and mentor late Prof. Pravin Visaria for nurturing and mastering me to understand various concepts and definitions used in the data collected in different Rounds of the National Sample Survey Organisation (Ministry of Statistics and Programme Implementation, New Delhi). I am thankful to Prof. Leela Visaria and Prof. N Lalitha of Gujarat Institute of Development Research, Ahmedabad for their useful comments on the earlier version of the paper as well as to Dr. Biplab Dhak of A.N. Sinha Institute of Social Studies, Patna for help in data analysis of the NSS 2014 dataset.

\section{Compliance with ethical standards}

Conflict of interest The author declares that he has no conflict of interest.

Open Access This article is licensed under a Creative Commons Attribution 4.0 International License, which permits use, sharing, adaptation, distribution and reproduction in any medium or format, as long as you give appropriate credit to the original author(s) and the source, provide a link to the Creative Commons licence, and indicate if changes were made. The images or other third party material in this article are included in the article's Creative Commons licence, unless indicated otherwise in a credit line to the material. If material is not included in the article's Creative Commons licence and your intended use is not permitted by statutory regulation or exceeds the permitted use, you will need to obtain permission directly from the copyright holder. To view a copy of this licence, visit http://creativecommons.org/licenses/by/4.0/.

\section{References}

Berman P, Ahuja R, Bhandari L (2010) The Impoverishing Effect of Health Care Payments in India: New Methodologies and Findings. Econ Political Wkl 45(16):65-71

Government of India (2013) Economic characteristics of unincorporated non-agricultural enterprises (excluding construction) in India, NSS 67th Round (JULY 2010-JUNE 2011). Report No. 549 $(67 / 2.34 / 2)$, February 2013. National Sample Survey Office, Ministry of Statistics and Programme Implementation, New Delhi 
Government of India. (2019). Key Indicators of Social Consumption in India: Health. NSS 75th Round (July 2017-June 2018), Report No. NSS KI (75/25.0), November 2019. New Delhi: Ministry of Statistics and Programme Implementation

Gumber A, Berman P (1997) Measurement and Pattern of Morbidity and the Utilization of Health Services: Some Emerging Issues from Recent Health Interview Surveys in India. J Health Popul Developing Ctries 1(1):16-43

Gumber A (1997) Burden of Disease and Cost of Ill Health in India: Setting Priorities for Health Interventions during the Ninth Plan. Margin 29(2):133-172

Gumber A (2000) Health Care Burden on Households in the Informal Sector: Implications for Social Security Assistance. Indian J Labour Econ 43(2):277-291

Gumber A, Kulkarni V (2000) Health Insurance for Informal Sector: Case Study of Gujarat. Econ Political Wkl 35(40):3607-3613

Gumber A. (2002). Economic Reforms and the Health Sector: Towards Health Equity in India. In: Institute of Applied Manpower Research (Eds) Reform and Employment (pp. 235-284). New Delhi: Concept Publishing House

Gumber A. (2016). National Sample Survey (NSS) Rounds on Morbidity and Healthcare Utilisation: Reflections on Concepts, Definitions, measurement and Analysis of Data. In $5^{\text {th }}$ Annual Conference of Indian Health Economics \& Policy Association (IHEPA), Kolkata https://www.researchgate.net/publicatio n/312085030_National_Sample_Survey_NSS_Rounds_on_Morbidity_and_Healthcare_Utilisation_ Reflections_on_Concepts_Definitions_Measurement_and_Analysis_of_Data

Gumber A., Lalitha N., Dhak B. (2017). Rising Healthcare Costs and Universal Health Coverage in India: An Analysis of National Sample Surveys, 1986 -2014. Working Paper No. 246. Ahmedabad: Gujarat Institute of Development Research. https://shura.shu.ac.uk/id/eprint/21618

Hooda S.K. (2015). Private Sector in Healthcare Delivery Market in India: Structure, Growth and Implications. ISID Working Paper 185. New Delhi: Institute for Studies in Industrial Development. https:// isid.org.in/pdf/WP185.pdf

Sen G, Iyer A, George A (2002) Structural Reforms and Health Equity: A Comparison of NSS Surveys 1986-87 and 1995-96. Econ Political Wkl 37(14):1342-1352

Sundararaman T, Muraleedharan VR (2015) Falling Sick, Paying the Price NSS $71^{\text {st }}$ Round on Morbidity and Costs of Healthcare. Econ Political Wkl 50(33):17-20

World Bank (2001) India-Raising the Sights Better Health Systems for India's Poor. Washington D.C.: World Bank

World Health Organization (2015) Tracking Universal Health Coverage: First global monitoring report. WHO, Geneva

United Nations Development Programme (UNDP) (2014) Maharashtra Human Development Report 2012. Sage Publications, New Delhi

Publisher's Note Springer Nature remains neutral with regard to jurisdictional claims in published maps and institutional affiliations. 